\title{
A EMPATIA FREIREANA NA ALFABETIZAÇÃO POPULAR: CONCEPÇÕES DA CIBERCULTURA EM TEMPOS DE PANDEMIA
}

\author{
FREIREANA EMPATHY IN POPULAR LITERACY: \\ CONCEPTIONS OF CYBERCULTURE IN TIMES OF PANDEMIC
}

\section{LA EMPATÍA FREIREANA EM LA ALFEBETIZACIÓN POPULAR: CONCEPCIONES DE CIBERCULTURA EN TIEMPOS DE PANDEMIA}

\section{RESUMO}

A Educação de Jovens e Adultos (EJA) foi a base do trabalho do educador Paulo Freire. Na sua luta política e social, a alfabetização nas comunidades populares seria uma porta de saída para a tomada de consciência crítica da realidade. Na Educação a conceituação de empatia como uma relação importante entre o professor e o aluno para o processo afetivo-educacional. Paulo Freire afirmava que a empatia no contexto da sala de aula ocorre quando o professor "pegar os olhos dos alunos emprestados" para que ele possa perceber de fato a realidade com que está interagindo. Quando se identifica a realidade do outro, percebe-se de perto os problemas e circunstâncias vividas sobretudo em ambientes de necessidade e privações, quando o outro percebe que nossa realidade é entendida fica mais aberto a ser acolhido por um estranho ou no caso um professor que vem trazer o conhecimento, esta é a empatia de Freire. A partir do ano de 2020, diante do contexto da pandemia do COVID-19, a empatia torna-se um processo coletivo de reprimir o isolamento social e proporciona conforto aos segmentos impactados pelo contexto pandêmico, para lograr êxito a cibercultura atuou como um fio condutor no processo pedagógico. Assim no presente trabalho é importante pesquisar a similitude da educação com a empatia libertadora de Paulo Freire em face da educação e cibercultura.

PALAVRAS-CHAVE: Paulo Freire. Empatia. Educação de Jovens e Adultos. Pandemia do COVID-19. Cibercultura.

Submetido em: 22/07/2021 - Aceito em: 08/10/2021 - Publicado em: 13/10/2021

${ }^{1}$ Mestre em Administração Pública pela Fundação Getúlio Vargas/RJ. Bacharel em Direito, PósGraduando em Gestão Pública Governamental pela Universidade Federal Rural de Pernambuco UFRPE. Aluno-especial do Doutorado em Educação e Novas Tecnologias pela Uninter.

${ }^{2}$ Doutora em Educação (Universidade de Lisboa), com pesquisa financiada pela Fundação da Ciência e Tecnologia - FCT-Portugal. Professora do Programa de Pós-Graduação - Mestrado e Doutorado em Educação e Novas Tecnologias.

${ }^{3}$ Publicitária, Mestranda pelo Programa de Mestrado Profissional em Educação e suas Novas Tecnologias- Centro Universitário Internacional-UNINTER/PR, Pós-Graduada em Gestão Escolar pela Faculdade Unina do Paraná.

4 Turismóloga pela Faculdade FASIPE, Mestranda pelo Programa de Mestrado Profissional em Educação e suas Novas Tecnologias- Centro Universitário Internacional-UNINTER/PR, PósGraduada em Gestão e Coordenação Escolar, Faculdade Eficaz/PR. 
The youth and Adult Education (EJA) was the basis of the work of educator Paulo Freire. In their political and social struggle, literacy in popular communities would be a way out for a critical awareness of reality. In Education, the concept of empathy as an important relationship between teacher and student for the affectiveeducational process. Paulo Freire stated that empathy in the context of the classroom occurs when the teacher "catch the eyes of borrowed students" so that he can actually perceive the reality with which he is interacting. When the reality of the other is identified, the problems and circumstances experienced are closely observed, especially in environments of need and deprivation, when the other realizes that our reality is understood, they are more open to being welcomed by a stranger or, in this case, a teacher who comes to bring knowledge, this is Freire's empathy. From the year 2020, in the context of the COVID-19 pandemic, empathy becomes a collective process of repressing social isolation and providing comfort to segments impacted by the pandemic context, in order to achieve success, cyberculture acted as a common thread in the pedagogical process. Thus, in the present work, it is important to research the similitude of education with Paulo Freire's liberating empathy in the face of education and cyberculture.
\end{abstract}

KEYWORDS: Paulo Freire. Empathy. Youth and Adult Education. COVID-19 Pandemic. Cyberculture.

\title{
RESUMEN
}

La Educación de Jóvenes y Adultos (EJA) fue la base del trabajo del educador Paulo Freire. En su lucha política y social, la alfabetización en las comunidades populares sería una salida para una conciencia crítica de la realidad. En Educación, el concepto de empatía como relación importante entre docente y alumno para el proceso afectivoeducativo. Paulo Freire afirmó que la empatía en el contexto del aula se produce cuando el profesor "capta la atención de los estudiantes prestados" para que pueda percibir la realidad con la que está interactuando. Cuando se identifica la realidad del otro, se observan de cerca los problemas y circunstancias vividas, sobre todo en entornos de necesidad y privación, cuando el otro se da cuenta de que se comprende nuestra realidad, está más abierto a ser acogido por un extraño o, en este sentido, caso, un maestro que viene a traer conocimiento, esa es la empatía de Freire. A partir del año 2020, en el contexto de la pandemia COVID-19, la empatía se convierte en un proceso colectivo de reprimir el aislamiento social y brindar consuelo a los segmentos impactados por el contexto pandémico, para lograr el éxito, la cibercultura actuó como hilo conductor en la pedagogía. proceso. Así, en el presente trabajo es importante investigar la similitud de la educación con la empatía liberadora de Paulo Freire frente a la educación y la cibercultura.

PALABRAS CLAVE: Paulo Freire. Empatía. Educación de jóvenes y adultos. Pandemia de COVID-19. Cibercultura.

\section{INTRODUÇÃO}

O centenário de Paulo Freire coloca em revelo toda sua luta no processo de alfabetização das camadas populares, contudo o Método desenvolvido pelo insigne pedagogo utilizava certamente o tema da empatia como uma de suas principais ferramentas de letramento, na sua proposta educacional libertadora e utilizando a perspectiva de se colocar no lugar do outro, como uma das premissas basilares do pensar freireano na sua perspectiva crítico-emancipatória.

Partindo da premissa do pensamento de Freire de que a educação, por si só, é um ato político por imbuir ao ensino a responsabilidade e o compromisso com a formação do indivíduo como um ser social e, que por muitas vezes, esses sujeitos que tiveram o direito à educação negado 
durante muitos anos, tenham tal direito efetivado, principalmente na Educação de Jovens e Adultos, torna-se uma problemática a ser apresentada no contexto deste artigo.

Compartilha-se neste trabalho do pensamento do educador Paulo Freire sobre a alfabetização, que vai muito além da leitura das palavras isoladas de um universo existencial, a alfabetização está relacionada à criação e recriação do sujeito sobre seu contexto espacial, social e cultural.

Neste sentido, este trabalho como tema de pesquisa, o contexto da empatia em face da EJA numa a discussão crítica que leva em consideração a inserção do homem no mundo e em diálogo com o mundo, na elaboração de atividades e escolha de temas geradores, já que "as visões impregnadas de anseios, de dúvidas, de esperanças ou desesperanças que implicam temas significativos, à base dos quais se constituirá o conteúdo programático da educação" (FREIRE,2014, p.116).

Assim, em tempos de pandemia da COVID-19, o objeto desse estudo volta-se na utilização da empatia no contexto educacional, que torna a empatia uma palavra de ordem para 2021, como explica Elaine Di Sarno (2020):

Aí que entra a empatia, que consiste na habilidade de perceber o outro, muitas vezes, sem que ele precise dizer algo acerca de sua situação emocional ou afetiva. A empatia significa colocar-se no lugar do outro, sentir suas emoções. Neste momento difícil, precisamos demonstrar interesse genuíno e ativo diante das preocupações [...] Não se sabe até quando, mas continuaremos vivenciando a pandemia em 2021, o que nos leva a questionar como e por quem serei cuidadoso.

O problema que será discutido, trata da cultura freireana da EJA, atualmente está-se no meio do processo de mudanças dos paradigmas da educação promovidos pela pandemia da COVID19 e pelas novas formas de letramento resultantes do processo tecnológico que avançam a saltos cada vez mais altos, dificultando o empoderamento das ferramentas de Tecnologias da Informação e Comunicação (TICs) e das novas competências até para os docentes, que se pensará dos jovens e adultos, em bases sociais menos favorecidas e sem acesso a cibercultura?

Voltam-se para as discussões que se avolumam pelos stakeholders da comunidade acadêmica, na controvérsia de como se instituirão as novas ferramentas de Tecnologias da Informação e Comunicação (TICs) na perspectiva da EJA e da cibercultura, "ainda carentes de maiores diálogos com o pensamento de Paulo Freire - caracteriza-se por formas emergentes e complexas de ser e estar (e, por conseguinte, de pensar, agir e comunicar) no ciberespaço e no mundo" (COSTA et al., 2020, p. 17-18). 
O contexto hodierno vislumbrado na sociedade do conhecimento é um processo evolutivo natural próprio do saber humano, contudo, tornar-se-á necessário romper com o paradigma entre o avanço do conhecimento por meio da tecnologia, que promove ainda uma massificação e hogeneinização dos saberes, com a educação que projeta o acervo cultural e a consciência crítica do ser humano, fazendo com que tecnologia e educação sejam caminhos convergentes e não processos de dominação, deste ponto epistemológico, extrai-se a justificativa deste trabalho.

Sobre a tecnologia que gera conhecimento, Manuel Castells um dos entusiastas da Sociedade em Rede defendia que a "tecnologia, entendida como cultura material, é uma dimensão fundamental da estrutura social e da mudança social" (2004, p. 29). Entretanto o autor alertava para o etiquetamento da sociedade do conhecimento, sendo ela uma fonte de poder e a tecnologia agindo como fonte de poder, atuaria no sentido inverso da mudança social, onde surge o paradigma tecnológico:

\begin{abstract}
Então, se a informação e o conhecimento são os principais fatores de poder e riqueza em todas as sociedades, é enganoso conceituar nossa sociedade como tal, mesmo que, pela razão prática de fazer comunicação mais fácil, cedi à moda dos tempos nas minhas etiquetas ao caracterizando nosso período histórico como a "era da informação". O que realmente queremos dizer, e o que sempre quis dizer, é que nossa sociedade é caracterizada pelo poder embutido na tecnologia da informação, no coração de um totalmente novo paradigma tecnológico. (CASTELLS, 2004, p. 28, traduzido pelos autores).
\end{abstract}

A visão de Castells sobre o paradigma tecnológico acompanha o pensamento de Freire, sempre crítico de processos de subjugação dos esquemas de poder das oligarquias, temia que a tecnologia promovesse formas de dominação das camadas populares, explicava Freire que "a tecnologia deixa de ser percebida como uma das grandes expressões da criatividade humana e passa a ser tomada como uma espécie de nova divindade a que se cultua" (FREIRE, 1981, p. $68)$.

$\mathrm{Na}$ expressão "divindade que se cultua" o pedagogo já antevia o que a tecnologia se transformaria nos tempos atuais, numa forma de opressão discreta, uma ideologia de direcionamento das atitudes humanas para uma única forma de pensar, onde todos são canalizados e forçados de comportamentos e atitudes repetidas, sem um processo crítico e revolucionário continuado.

Por fim, este trabalho é concebido numa abordagem epistemológica para a construção do desenho no qual foi norteado no Método Paulo Freire de Educação de Jovens e Adultos, a partir do qual o processo da EJA era proposto na perspectiva crítico-libertadora, sendo uma 
abordagem constante e continua no seu pensamento e objeto frequente em suas obras, a preocupação com esses extratos sociais menos favorecidos.

Qualquer atividade da ciência da educação envolve o processo de pesquisa, sendo seu núcleo, visando aproximação e entendimento de uma realidade, sendo um processo permanente e sem findar a tentativa de progressiva da realidade, na vocação de encontrar verdades sobre um objeto pesquisado (Gerhardt et al, 2009).

Suscitando as reflexões sobre a prática educativa e docente, o referencial teórico terá como base justamente a quanto aos procedimentos a pesquisa histórico-bibliográfica em livros, periódicos e na questão da pandemia da COVID-19 e suas ligações com a cibercultura, articulando-os com o campo pedagógico.

\section{EMPATIA COMO UMA CONSTRUÇÃO ENTRE O PROFESSOR E O ALUNO}

O termo empatia deriva da palavra grega "empatheia", que significa "paixão" ou "ser muito afetado" Esse conceito é também apresentado através do termo alemão Einfühlung que tem sua significação acerca do processo de imitação interna, que ocorre a partir da apreciação de objetos de arte, empatia por objetos inanimados (SAMPAIO; CAMINO; ROAZZI, 2009).

A construção da palavra empatia e seu significado perpassou do campo das artes para o campo da psicologia, novamente explicam Sampaio; Camino; Roazzi (2009, p. 213):

\footnotetext{
No que diz respeito à Psicologia, o primeiro autor a traduzir o termo Einfühlung por empathy foi Titchener, em 1909. Na concepção desse estruturalista norte-americano, o conceito de Einfühlung descrevia a capacidade de conhecer a consciência de outra pessoa e de raciocinar de maneira análoga a ela através de um processo de imitação interna.
}

As ciências e seus termos se comunicam, então o termo empatia saiu do campo da psicologia e migrou para o campo da ciência pedagógica. A visão epistemológica deste trabalho é apresentar a conceituação da empatia na relação entre o professor e o aluno.

Conforme explica Brunezzi, a "relação com o trabalho da orientação de pessoas e a atividade de ensinar foi primeiramente apresentada por Rogers na década de 70 do século passado que a relação entre empatia e educação foi estabelecida". (Brunezzi, 2014, p.131). 
Carl Rogers um psicólogo americano que promoveu um modelo de estudos chamado Terapia Centrada nas Pessoas (TPC) associou o trabalho do professor ao trabalho do orientador ou terapista, enquanto o aluno ficou com o papel do cliente ou paciente, Rogers afirmava:

Um alto grau de empatia talvez seja o fator mais relevante numa relação, sendo, sem dúvida, um dos fatores mais importantes na promoção de mudanças e de aprendizagem. [...] quando o professor demonstra que compreende o significado, para o aluno, das experiências em sala de aula, a aprendizagem melhora (ROGERS, 1977, p.42).

Vigostki foi psicólogo que atuou no campo educacional, nas questões relacionadas a empatia, trabalhando os conceitos do desenvolvimento cognitivo e da relação do professor com o aluno, propondo ao pedagogo a mediação do aprendizado através de estratégias, que levam o aluno a aprender por si mesmo numa relação estimulada de independência e conhecimento potencial.

Com isso desenvolveu o que veio a ser conhecido como Zona de Desenvolvimento Proximal (ZDP), "ela é constituída por dois tópicos separados: primeiro, a relação geral entre aprendizado e desenvolvimento; e, segundo, os aspectos específicos dessa relação quando a criança atinge a idade escolar" (VIGOTSKI, 1991, p. 56).

A virtude de observar o mundo através dos olhos de outra pessoa para poder entender como ela se sente (afetividade), como ela compreende as coisas que a cercam (cognição) sem deixar de observar a própria visão de mundo e de sentimentos (emoções), estes componentes são apontados por Nunes:

A empatia envolve em termos gerais três componentes: afetivo, cognitivo e reguladores de emoções. O componente afetivo baseia-se na partilha e na compreensão de estados emocionais de outros. $\mathrm{O}$ componente cognitivo refere-se à capacidade de deliberar sobre os estados mentais de outras pessoas. A regulação das emoções lida com o grau das respostas empáticas (NUNES, 2018, p.3).

Assim, o professor como propedeuta da pedagogia é conduz a atividade cognitiva, assim cabe ao docente a atuação principal em compreender e analisar o aluno por dentro, isto é a empatia.

No contexto da pandemia a relação da empatia entre o professor e o aluno deve ser conduzida de modo a dar apoio mútuo pois ambos passam por situações de isolamento social, incertezas e outras inseguranças que levam a provocar danos a saúde mental, claro que o professor, tem uma relação de maior conhecimento e segurança do que o aluno e atua de forma a dar apoio então "o melhor que se pode fazer é se valer da empatia e tentar agir de modo a contribuir com 
os menos favorecidos. Não é fácil, mas é necessário. É premente desenvolver um olhar empático para o outro" (OLIVEIRA; SANTOS; FLORÊNCIO, 2019, p. 11).

Em recente entrevista respondeu o Educador António Nóvoa (2021) sobre os caminhos da escola do futuro e sua transformação pós pandêmica, defendendo que a transformação do modelo escolar já deveria haver começado, com os novos modelos de tecnologias e inteligências artificiais, que alguns refreiam em não aceitar, a nova dinâmica do conhecimento "porque para as crianças a relação humana, olhos nos olhos, corpo no corpo, é essencial[...]Isso é absolutamente essencial para a escola do futuro: ter as dimensões cognitivas e de empatia, de curar, cuidar, tratar." (Nóvoa, 2021).

Trabalhar a empatia já era uma situação corriqueira de necessidade entre professor e aluno nos tempos pós pandêmicos tornou-se uma imperatividade, é a visão do olhar do outro do qual Freire se referia.

\section{A VISÃO FREIREANA NA CONSTRUÇÃO DA EMPATIA NO LETRAMENTO DAS CAMADAS POPULARES}

As bases da Educação de Jovens e Adultos (EJA) foram fonte do trabalho do educador Paulo Freire. Na sua luta política e social, a alfabetização de jovens adultos nas comunidades populares seria uma porta de saída para a tomada de consciência crítica da realidade que os cercava, assim torna-se relevante observar na obra de Paulo Freire e cuidado com a EJA que não possuía bases sociais as classes populares.

O contexto de vida do educador no Recife, convivendo com os resquícios cultura da cana-deaçúcar. Freire expressa sua crítica a educação de adultos no modelo instrumental vigente, "a questão está em que pensar autenticamente é perigosa. O estranho humanismo desta concepção 'bancária' se reduz à tentativa - de fazer dos homens o seu contrário - o autômato" (FREIRE, 2014, p. 35).

A empatia pode-se dizer que foi uma marca constante na obra de Paulo Freire ele buscava a compreensão dos iletrados e sua visão de mundo era no sentido de entender com os "olhos" dos outros.

A modernização, como já foi dita na sessão anterior era um temor do pedagogo. Freire acreditava no processo natural de modernização, mas suspeitava no malogro da tecnologia pela instrumentalidade da manipulação do indivíduo, não possibilitando uma transformação real, 
operando as tecnologias como mais uma forma de poder que não geraria o desenvolvimento crítico pessoal:

Embora esta concepção mecanicista pretenda identificar sua ação modernizante com o desenvolvimento, parece-nos que é preciso distinguir uma do outro. Na modernização, de caráter puramente mecânico, tecnicista, manipulador, o centro de decisão da mudança não se acha na área em transformação, mas fora dela. A estrutura que se transforma não é sujeito de sua transformação. No desenvolvimento, pelo contrário, o ponto de decisão se encontra no ser que se transforma e seu processo não se verifica mecanicamente. Desta maneira, se bem que todo desenvolvimento seja modernização, nem toda modernização é desenvolvimento. (FREIRE, 1983, p.38, grifos dos autores).

Freire acreditava na práxis da educação da EJA como um processo de ajudar pessoas a juntar teoria e prática, o fazer e o pensar, lecionava o autor "a educação das crianças, dos jovens e dos adultos tem uma importância muito grande na formação do homem novo e da mulher nova. [...] Uma educação que dê valor à ajuda mútua e não ao individualismo, que desenvolva o espírito crítico e a criatividade, e não a passividade" (FREIRE, 1989, p.48).

O professor Walter Kohan da UERJ, em entrevista sobre o livro de sua autoria: Paulo Freire, mais do que nunca, defendeu a práxis de vida de Paulo Freire na EJA, afirmando "o que pode surpreender muitos pois Paulo Freire foi, um educador de adultos é a meu ver, umas palavras mais importantes para Paulo Freire e diz respeito não a uma idade, mas a uma atitude curiosa, perguntadora, inquieta de uma vida educadora" (KOHAN, 2019, p.12).

A EJA só teve maiores proporções e começou a se ter uma reflexão pedagógica, com o educador brasileiro Paulo Freire, "no começo dos anos 1960, Freire trouxe uma nova perspectiva, quebrando com paradigmas. Sua visão era uma educação libertadora que trouxesse a emancipação do sujeito que era tido como ignorante e que não conseguia atuar na sociedade, sendo obrigado a se sujeitar a trabalhos inferiores" (DOMINSCHEK; PILLETTI, 2020, p. 459).

Na ocasião Freire formou seu método de alfabetização compostos de cinco fases, em todas podem ser observadas a empatia como forma de letramento das classes populares, conforme explicam PEREIRA; PIA; FIGUEIRÊDO (2018, p.6) sobre o método Paulo Freire:

O método de alfabetização elaborado por Freire é composto por cinco fases esse método de alfabetização que até os dias atuais é trabalho com algumas adaptações, mas seguindo a lógica inicial de Freire, onde busca a partir de palavras geradoras, iniciar a aprendizagem da realidade dos sujeitos da educação popular, pois para alcançar esse sujeito primeiro havia a necessidade de saber o universo de Vocabulário desses sujeitos, posteriormente selecionar esses vocabulários a terceira fase seria construção de um ambiente para aplicação de situações problemas para os grupos a quarta consiste em fichas roteiros, que auxiliem os coordenadores de debate nó seu 
trabalho por fim elaboração de fichas com a decomposição das famílias fonêmicas correspondentes aos vocábulos geradores.

O Quadro 1 apresenta-se o faseamento do Método com as principais elaborações práticas, destacando-se toda sistemática de aproximação emocional, cultural, antropológica e dialógica, traduzindo-se numa empatia entre os docentes e os iletrados, construída pela proximidade do Método freireano com a realidade que cerca o aluno:

Quadro 1. Método Paulo Freire de Alfabetização

\begin{tabular}{|c|c|}
\hline Fases de elaboração & Execução prática \\
\hline $\begin{array}{l}\text { 1. Levantamento do universo } \\
\text { vocabular dos grupos com quem } \\
\text { se trabalhará. }\end{array}$ & $\begin{array}{l}\text { Este levantamento é feito através de encontros informais com os } \\
\text { moradores da área a ser atingida, e em que não só se fixam os } \\
\text { vocábulos mais carregados de sentido existencial e, por isso, de } \\
\text { maior conteúdo emocional, mas também os falares típicos do } \\
\text { povo. Suas expressões particulares, vocábulos ligados à } \\
\text { experiência dos grupos, de que a profissional é parte. }\end{array}$ \\
\hline $\begin{array}{l}\text { 2. A segunda fase é constituída } \\
\text { pela escolha das palavras, } \\
\text { selecionadas do universo } \\
\text { vocabular pesquisado. }\end{array}$ & $\begin{array}{l}\text { Seleção a ser feita sob critérios: a) o da riqueza fonêmica; b)o das } \\
\text { dificuldades fonéticas (as palavras escolhidas devem responder } \\
\text { às dificuldades fonéticas da língua, colocadas numa sequência } \\
\text { que vá gradativamente das menores às maiores dificuldades); c) } \\
\text { o de teor pragmático da palavra, que implica numa maior } \\
\text { pluralidade de engajamento da palavra numa dada realidade } \\
\text { social, cultural, política, etc. }\end{array}$ \\
\hline $\begin{array}{l}\text { 3. A terceira fase consiste na } \\
\text { criação de situações existenciais } \\
\text { típicas do grupo com quem se vai } \\
\text { trabalhar. }\end{array}$ & $\begin{array}{l}\text { Estas situações funcionam como desafios aos grupos. São } \\
\text { situações-problemas, codificadas, guardando em si elementos } \\
\text { que serão descodificados pelos grupos, com a colaboração do } \\
\text { coordenador. O debate em torno delas irá, como o que se faz com } \\
\text { as que nos dão o conceito antropológico de cultura, levando os } \\
\text { grupos a se conscientizarem para que concomitantemente se } \\
\text { alfabetizem. Nelas vão se colocando os vocábulos geradores, na } \\
\text { gradação já referida, de suas dificuldades fonéticas }\end{array}$ \\
\hline $\begin{array}{l}\text { 4. A quarta fase consiste na } \\
\text { elaboração de fichas- roteiro, que } \\
\text { auxiliem os coordenadores de } \\
\text { debate no seu trabalho }\end{array}$ & $\begin{array}{l}\text { Estas fichas-roteiro devem ser meros subsídios para os } \\
\text { coordenadores, jamais uma prescrição rígida a que devam } \\
\text { obedecer e seguir. }\end{array}$ \\
\hline 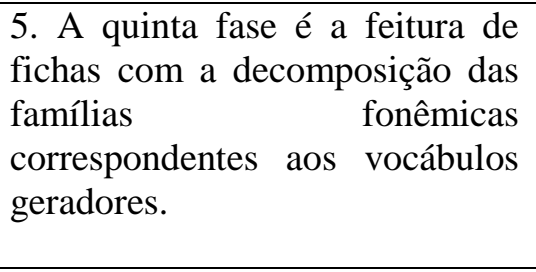 & $\begin{array}{l}\text { Atitude dialogal à qual os coordenadores devem converter-se } \\
\text { para que façam realmente educação e não "domesticação". } \\
\text { Exatamente porque, sendo o diálogo uma relação eu-tu, é } \\
\text { necessariamente uma relação de dois sujeitos. Toda vez que se } \\
\text { converta o "tu" desta relação em mero objeto, se terá pervertido } \\
\text { o diálogo e já não se estará educando, mas deformando. }\end{array}$ \\
\hline
\end{tabular}

Fonte: Freire (2011, p.111-114). Elaborado pelos autores.

Assim, tem-se no Método, "a afetividade está presente na empatia, na amizade, na amorosidade, no cuidado, na proteção, no diálogo, além do desenvolvimento ético e estético que é resultado da vivência entre os sujeitos" (FURLAN; PIGATTO; HENNICKA, 2019, p.87-88). 
Pensando-se na temática a ser abordada em sala de aula, levamos em consideração o contexto da pandemia do COVID-19 e demais acontecimentos, principalmente políticos, que vêm acontecendo no Brasil e mundo e que nos provoca a necessidade de se ter alteridade em tempos tão difíceis. Sendo assim, decidiu-se pesquisar a discussão sobre "empatia", a fim de que os educandos reflitam criticamente sobre sua situação existencial (Freire, 2014), concreta e seus problemas, desafiando-os a respostas não apenas em nível intelectual como no nível da ação.

A amorosidade e a empatia da alfabetização freireana em tempos de COVID-19 está mais hodierna e leva a tranquilizar o ambiente escolar na insegurança das relações entre professor e aluno.

\section{CONCEPÇÕES DA CIBERCULTURA EM TEMPOS DE PANDEMIA}

O cenário de saúde pública atual ainda pandêmico é vivido, pois não cessarão a gestões necessárias ao passo seguinte de controle da COVID-19, ainda estamos na etapa de vacinação e num ambiente cheio de incertezas quando aos tratamentos, pois embora ainda vivenciamos os embargos sociais e sanitários.

Contudo no contexto das TICs e das novas ferramentas de internet, dada a velocidade de transformação do conhecimento em termos de tecnologia, ultrapassou-se a etapa da pandemia. Em educação, as metodologias ativas, as competências e os modelos pedagógicos, em especial no ensino superior já utilizam a linguagem e currículos que costumam ser chamados cenários pós-pandêmicos.

A tecnologia educacional já se posicionou à frente do contexto de saúde, claro que muito impulsionada pelo mercado e pela Instituições de Ensino Superior, que tiveram que dar vazão a educação no ciberespaço para promover o conhecimento.

A cibercultura que foi definida por Lévy (1999, p. 17) como "[...] conjunto de técnicas (materiais e intelectuais), de práticas, de atitudes, de modos de pensamento e de valores que se desenvolvem juntamente com o crescimento do ciberespaço", agora toma outra dimensão pois o processo tecnológico já avançava naturalmente na educação. Conceitua-se à cibercultura que "consiste em um conjunto de transformações epistemológicas e culturais de inúmeras ordens" (COSTA et al., 2020, p. 30).

Em tempos de sociedade do conhecimento "as faculdades e escolas de pedagogia mantêm, basicamente, a mesma orientação e estrutura desde o último quarto do século passado, não 
tendo adotado as redefinições e os redesenhos que seriam necessários para abordar os desafios da sociedade da informação" (BRUNNER, 2004, p. 71).

Contudo será preciso posicionar a EJA no contexto da pandemia e da cibercultura para buscar os novos modelos de ensino desses extratos, contudo não há um malogro entre o que pensava Freire em sentido de tecnologias e o atual cenário, como explicam "dentre os muitos tópicos que podem ilustrar a atualidade da epistemologia freireana [...]debater a atual efervescência tecnológica, que não deixa de transformar radicalmente nossa educação e nossos entendimentos sobre as formas de ensinar e aprender" (COSTA; BEVILÁQUA; FIALHO, 2020, p.1).

Quadro 2. Dimensão da Empatia na Educação de Jovens e Adultos em Freire.

Assegurar o direito à educação básica aos jovens e adultos, por isso o compromisso dos governos em garantir a continuidade dos estudos;

Recuperar a dimensão política da prática educativa, desafiando a todos os educadores para uma permanente revisitação teórica e lúcida crítica da prática, que irá se consubstanciar na reinvenção e aproximação coerente entre teoria e prática.

Elaborar um Plano Político Nacional de Alfabetização para Jovens e Adultos, no contexto da Educação Básica, que servirá como diretriz para os Projetos Político - Pedagógicos das Escolas Públicas e particulares, contemplando, no processo da alfabetização, as reais necessidades e interesses das classes trabalhadoras e contextualizando, assim, sua realidade social, econômica e cultural.

Proporcionar na educação, a Aprendizagem ao Longo da Vida, um direito já garantido na LBD e condição para a participação na sociedade do conhecimento do século XXI. As novas exigências da sociedade suscitam expectativas que solicitam que toda pessoa siga renovando seus conhecimentos e capacidades ao longo de toda a vida.

Reconhecer e reafirmar a diversidade de experiências que constituem a educação de jovens e adultos, o que significa abrir-se a distintos âmbitos e à convergência entre eles. A meta última deverá ser a criação de uma sociedade educativa.

Democratizar as relações na escola pública popular, efetivando uma vivência democrática e participativa nas decisões das prioridades da escola.

Dar oportunidade aos educadores, para que, no processo de reflexão-análise e reconstrução da prática-educativa, apropriem-se dos conhecimentos das últimas pesquisas sociolinguistas, visando à superação e desconstrução da visão preconceituosa em relação à linguagem das classes trabalhadoras;

Priorizar um ensino de qualidade, no sentido de assegurar que a escola pública popular, no período noturno, viabilize o acesso de toda a sua infraestrutura aos alunos jovens e adultos;

Reconhecer e formar o educador popular, com sua rica e vasta experiência, como profissional da Educação de Jovens e Adultos a fim de, receber, por seus serviços, salário compatível ao do educador do sistema educacional regular;

Assegurar o acesso as novas tecnologias ao público da EJA, que concorra para seu desenvolvimento crítico, não para sua manipulação ideológica e controle

Fonte: Adaptado de Lemos, 2010, p. 118 e 119. Elaborado pelos autores. 
Com efeito, por conclusão verifica-se que Freire um educador da EJA, nunca foi avesso ao acesso das camadas populares e das pessoas iletradas, aos avanços da cibercultura na educação "enfim, cabe lembrar que Freire nunca foi contra a tecnologia; aliás, foi defensor da socialização de conhecimentos de Informática e inclusão digital quando foi Secretário de Educação do Município de São Paulo” (SOFFNER, 2013, p. 154).

A inclusão digital das classes sociais menos favorecidas é um instrumento de apoio no acesso aos recursos tecnológicos, principalmente aos alunos que integram a rede de ensino pública.

\section{CONSIDERAÇÕES FINAIS}

Conclui-se que a empatia como um processo de catalizador da atuação pedagógica do professor em face do aluno possibilitou a psicoterapeutas como Carl Rogers, que promoveu que a terapia centrada nas pessoas (TPC) e Lev Vigostki que desenvolveu processos cognitivos conhecidos como zona de desenvolvimento proximal (ZDP), buscaram na empatia relacionada a docência uma maior aproximação entre o professor e o aluno.

Educadores da atualidade como António Nóvoa e Walter Kohan também espelham os valores da empatia como forma de superação das amarras do acesso as novas tecnologias pelos discentes, colocando o professor como o protagonista do processo de mudança nesta quadra do tempo.

Não se pode deixar de referenciar cibercultura e tecnologia em qualquer pesquisa acadêmica. Antes do contexto pandêmico, já a cibercultura estava arraigada no contexto da pesquisa e da ciência da Educação, agora passa a ser uma "mola mestra", uma porta de saída no pensamento pós-pandêmico.

A cibercultura por intermédio das TICs é a por onde o processor dará vazão a empatia com os alunos, aumentando o processo de aprendizado e buscando reflexões críticas sob a ótica do centenário de Paulo Freire e suas ideias e princípios.

O contexto da pandemia coloca o professor novamente nesta senda de ser empático e perceber às problemáticas decorrentes do isolamento social, a afetação mental e da exclusão das camadas populares mais sujeitas a exposição da pandemia, mas que não podem deixar de trabalhar ou estudar pois precisam sair do estado das coisas, do locus a que são submetidos e condenados a permanecer. 
A obra de Freire foi sem dúvida dedicada a suas inquietações com o letramento das pessoas das classes populares. O Método Freireano de alfabetização era muito maior do que o simples letramento de um jovem ou adulto, cuidava de desenvolver um senso de criticidade através do processo do conhecimento da realidade do alfabetizando. Era olhar a pessoa, seu lugar, seu ambiente de vida e desta realidade retirar os contextos de gestos, amorosidade, proximidade e alteridade.

Paulo Freire sempre esteve adiante no processo de alfabetização de jovens e adultos das camadas populares e com dialogicidade, amorosidade e o consequente sentimento empatia, sem deixar de lado a noção crítico-libertadora no seu processo pedagógico de fazer pessoas nascer para a vida.

\section{REFERÊNCIAS}

BROLEZZI. Antônio Carlos. Empatia na relação aluno/professor/conhecimento. Encontro Revista de Psicologia, Santo André, v. 17, n. 27, p. 123-131, 2014.

CASTELLS. Manuel. The network society: a cross-cultural perspective . In CASTELLS, Manuel. Informationalism: The Technological Paradigm of The Network Society. Northampton: Edward Elgar Publishing. 2004.

COSTA. Alan. Ricardo; BEVILÁQUA. André Firpo.; FIALHO. Vanessa Ribas. A atualidade do pensamento de Paulo Freire sobre as tecnologias: letramentos digitais e críticos. Revista Olhar de Professor. n. 23, pp. 01-16. Universidade Estadual de Ponta Grossa. 2020.

COSTA, Alan Ricardo, et al. Paulo Freire hoje na Cibercultura. Porto Alegre: Editora CirKula, 2020. 100p.

DI SARNO. Elaine. Empatia: palavra de ordem para 2021. Disponível em: https://topview.com.br/self/artigo-empatia-palavra-de-ordem-para-2021/. Acesso em 02 jul. 2021.

DOMINSCHEK. Desire Luciane; PILLETTI Gabriele de Andrade. A educação de jovens e adultos no século XXI: a expansão da educação a distância nesta modalidade de ensino. Interfaces Científicas. Aracajú, vol. 8, nº 3, p. 455-468, set. 2020.

FREIRE. Paulo. A importância do ato de ler: em três artigos que se completam. Autores Associados. São Paulo Cortez, 1989.

FREIRE. Paulo. Pedagogia do Oprimido. 57 Ed. Rio de Janeiro, Paz e Terra. 2014. 
FREIRE. Paulo. Pedagogia da Autonomia: saberes necessários à prática educativa. São Paulo: Paz e Terra, 2011.

FREIRE, Paulo. Ação cultural para a liberdade e outros escritos. Rio de Janeiro. Paz e Terra, 1981.

FREIRE. Paulo. Extensão ou comunicação? 7a ed. Rio de Janeiro, Paz e Terra, 1983.

FONTGALLAND, R. C.; MOREIRA, V. Da empatia à compreensão empática: evolução do conceito no pensamento de Carl Rogers. Memorandum: Memória e História em

Psicologia, [S. l.], v. 23, p. 32-56, 2012. Disponível em: https://periodicos. ufmg.br/index.php/memorandum/article/view/6554. Acesso em: 4 jul. 2021.

FURLAN. Fernanda; PIGATTO. Carolina Zasso; HENNICKA. Micheli Daiani. As relações dialógicas e afetivas em uma escola municipal de Santa Maria, RS. Fórum de Estudos Paulo Freire: Leituras de Paulo Freire (21.: 2019 maio 2-4) Anais do XXI Fórum de Estudos leituras de Paulo Freire / org. Fabiana Kaodoinski ...[et al.]. Caxias do Sul, RS: Educs, 2019.

GERHARDT, Tatiana Engel, et al. Estrutura do projeto de pesquisa. Porto Alegre: Editora da UFRGS, 2009.

KOHAN, Walter. Entrevista Paulo Freire, mais do que nunca. [Entrevista concedida a] Alexandra Lima da Silva/UERJ. Ednardo Monteiro Gonzaga do Monti/UFPI. Revista Caminhos da Educação: diálogos, culturas e diversidades. Teresina, Brasil, v. 1, n. 1, p. 10-12, janeiro/abril de 2019.

LEMOS, Silvania Donadio Vilela. A atualidade do pensamento de Freire na educação de jovens e adultos no século XXI. 2010. 187 f. Tese (Doutorado em Educação). Pontifícia Universidade Católica da São Paulo. São Paulo.

LÉVY, Pierre. Cibercultura. São Paulo: Editora 34, 1999.

NÓVOA, António. Aprendizagem precisa considerar o sentir. [Entrevista concedida a] Luciana Alvarez. Revista Educação. Jun. 2021. Disponível em: https://revistaeducacao.com .br/2021/06/25/antonio-novoa-aprendizagem-sentir/. Acesso em 30 jun. 2021.

NUNES, Denise Bacellar. Compreendendo os conceitos de empatia a partir de uma experiência pragmática em Competência em Informação (Coinfo): o Programa Jovens Talentos para a ciência da Universidade de Brasília - Unb. 2018. Disponível em: http://seminariohispano-brasileiro.org.es/ocs/index.php/viishb/viishbucm/paper/viewFile/306/ 29. Acesso em 04 jul. 2021.

OLIVEIRA, A. C. B. SANTOS, C. A. B.; FLORÊNCIO, R.Métodos e Técnicas de Pesquisa em Educação. Revista Cientifica da FASETE 2019.1. 2019. Disponível em: 


\section{Revista Docência e Cibercultura}

https://www.unirios.edu.br/revistarios/media/

revistas/2019/21/metodo_\%20etecnicas_de_pesquisa_em_educacao.pdf. Acesso em: 02 jul.2021.

OLIVEIRA, Evlyn Rodrigues (Org) et. al. Empatia e Cooperação. Liga Acadêmica de Terapia Cognitivo-Comportamental da Universidade do Estado do Rio de Janeiro (LATCCUERJ). 2020.Disponível em: file:///Users/felix/Downloads/Cartilha-EmpatiaeCooperao\%20 (1).pdf. Acesso em 03 jul. 2021.

PEREIRA, Ricardo Targino; PIA. Jeffersson da Silva; FIGUEIRÊDO. João Pedro dos Anjos. A educação popular dialogando com a educação emocional na construção de uma concepção da emoção empatia. 2018. Disponível em: https://editorarealize.com.br/editora /anais/conedu/2018/TRABALHO_EV117_MD1_SA18_ID3367_17092018180137.pdf. Acesso em: 05 jul. 2021.

ROGERS, Carl Ranson. A pessoa como centro. São Paulo: EPU, 1977.

SAMPAIO, Leonardo Rodrigues; CAMINO, Cleonice Pereira dos Santos; ROAZZI, Antonio. Revisão de aspectos conceituais, teóricos e metodológicos da empatia. Psicol. cienc. prof., Brasília, v. 29, n. 2, p. 212-227, jun. 2009. Disponível em: http://pepsic.bvaslud.org/scielo.ph p? script=sci_arttext\&pid=S141498932009000200002\&lng=pt\&nrm=iso. Acesso em 04 jul. 2021.

SOFFNER, Renato. Tecnologia e educação: um diálogo Freire - Papert. Tópicos Educacionais, Recife, n.1, p. 147-162, jan./jun. 2013.

VIGOSTKI, Lev Semyonovich. A formação social da mente. São Paulo: Martins Fontes, 1984.

Este é um artigo de acesso aberto distribuído sob os termos da Licença Creative Commons Atribuição Não Comercial-Compartilha Igual (CC BY-NC- 4.0), que permite uso, distribuição e reprodução para fins não comerciais, com a citação dos autores e da fonte original e sob a mesma licença. 